\title{
EFFECT OF VESICAL OVERDISTENTION ON BLADDER MUCIN
}

\author{
DAVID L. PERLOW, M.D. \\ PAUL W. GIKAS, M.D. \\ ELIOT M. HOROWITZ, M.D.
}

From the Section of Urology, Department of Surgery, and Department of Pathology, University of Michigan Medical Center, Ann Arbor, Michigan

\begin{abstract}
Histochemical staining of bladder tissue demonstrates a discrete layer of mucopolysaccharide (mucin) on the surface of human and rabbit bladders. Studies have shown that an intact mucin layer may be important in helping the bladder to resist bacterial infections. This report correlates vesical overdistention with destruction of the mucin layer in the rabbit bladder. These findings suggest that vesical overdistention may predispose to urinary tract infection because of bladder mucin disruption.
\end{abstract}

Most authorities agree that urinary infections occur primarily from a retrograde contamination into the bladder. ${ }^{1-4}$ When Escherichia coli are inoculated into "healthy" bladders, no urinary infection occurs. ${ }^{5}$ Similarly, patients on intermittent catheterization (not a sterile technique) frequently maintain uninfected urine without antibiotics. ${ }^{6}$ The reasons one bladder resists infection while another succumbs are not known.

To prevent urinary infections, Lapides has long advocated frequent voiding feeling that increased intravesical pressure disrupts the tissue integrity or blood supply to the bladder ${ }^{6-8}$ Investigations have shown that voiding is an important physical mechanism by which the bladder resists infection. ${ }^{9-11}$ Parsons and associates $^{12-14}$ have shown that bladder mucin has a significant role in the primary antibacterial defense of the bladder. Their data have shown the destruction of bladder mucin (by acid) to be associated with increased microbial attachment to the bladder. ${ }^{12,13}$

If the mucin layer of the bladder could be disrupted by vesical overdistention, we could more clearly correlate vesical overdistention with uri-

Presented at the Annual Meeting, American Urological Association, Inc., Boston, Massachusetts, May, 1981. nary tract infections. The data obtained from this experiment indicate that vesical overdistention disrupts or destroys the mucin layer of the rabbit bladder. On the basis of histochemical staining of these bladders, we were able to blindly predict, with 94-per cent accuracy, which bladders were normal and which had been overdistended.

Material and Methods

\section{Laboratory treatment}

Seventeen female New Zealand white rabbits weighing 2 to $4 \mathrm{Kg}$. were obtained for study. One of us (E.M.H.), in a random manner, chose some of the animals to be controls and some to be experimental. The experimental animals had their bladder necks ligated through a ventral midline incision. Twenty-four hours later they were sacrificed, as were the control animals. All rabbit bladders were excised, irrigated gently in normal saline, and placed in Bouin solution. The bladders were then sectioned and stained with colloidal iron. Colloidal iron stain is specific for mucin.

\section{Microscopic findings}

Two of us (D.L.P. and P.W.G.) then examined the stained bladder slides. On the basis of 

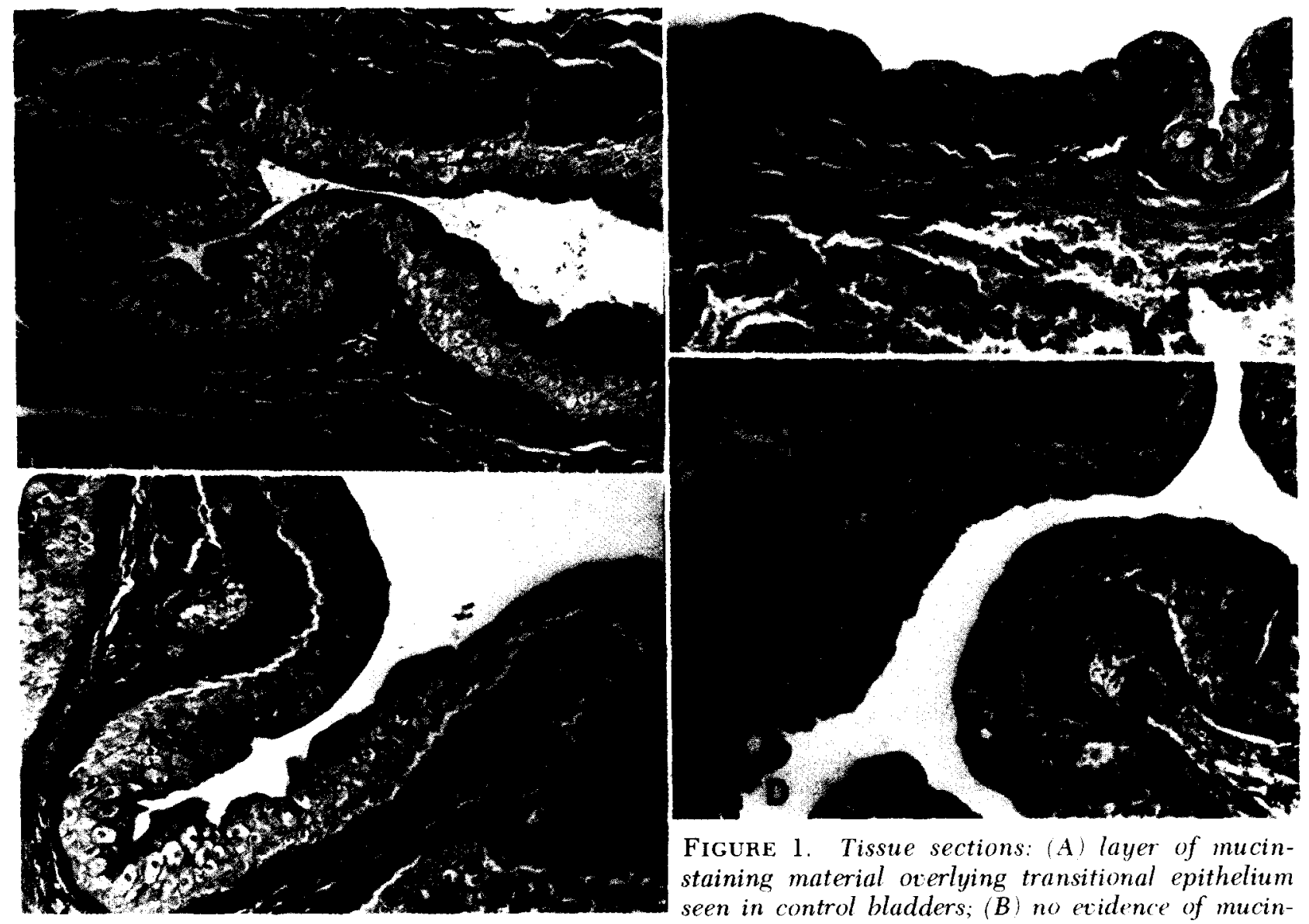

Figure 1. Tissue sections: (A) layer of mucinstaining material overlying transitional epithelium seen in control bladders; (B) no evidence of mucinstaining layer overlying transitional epithelium; $(C)$ disrupted mucin-staining layer; and $(D)$ presence and absence of mucin-staining layer in "mixed picture," about which no prediction was made.

the histochemical staining of the mucin, predictions were made as to whether tissue sections were from a control or an experimental bladder. On examination of 17 bladders, 3 were found to have an intact mucin layer. These were characterized by clear evidence of a mucin-staining layer overlving the transitional epithelium (Fig. 1A). These tissue sections were predicted to be from control bladders. Thirteen bladders were found to have an absent or significantly disrupted mucin-staining layer (Fig. 1B, C). These tissue sections were predicted to be from experimental bladders. One slide presented a "mixed picture" characterized by both the presence and absence of a mucin-staining layer (Fig. 1D). No prediction was made regarding this bladder.

\section{Results}

The correct study group (experimental or control) was predicted in 15 of 16 rabbits. This represented a 94-per cent accuracy and a $p$ value of $<0.0002$. The single error was in a control blad- der which had no recognizable mucin layer (perhaps this rabbit was an infrequent voider). The slide on which no prediction was made was a control bladder. The data are summarized in Table I.

\section{Comment}

Host antibacterial defenses of the lower urinary tract are multifactorial. They include the concepts of (1) mechanical bladder emptying, (2) bladder epithelial surface phenomenon, (3) bladder secretory properties, (4) urine properties, and (5) generalized or local cellular or humoral properties. ${ }^{15}$ Any discussion of lower urinary tract infection must recognize more than one single defense mechanism.

It is entirely plausible that the bacterial antiadherence effect of bladder mucin plays an important role in the primary defense to urinary tract infections. A significant amount of substantiating work has been done in this regard. ${ }^{12-14}$ Our data help to correlate vesical overdistention, increased intravesical pressure and, 
TABLE I. Results of predictions made in 17 experimental and control rabbits*

\begin{tabular}{clcl}
$\begin{array}{c}\text { Rabbit } \\
\text { Slide No. }\end{array}$ & $\begin{array}{c}\text { Mucin Layer } \\
\text { Description }\end{array}$ & $\begin{array}{c}\text { Control or } \\
\text { Experimental }\end{array}$ & $\begin{array}{c}\text { Prediction } \\
\text { Result }\end{array}$ \\
\hline 3326 & Absent/disrupted & $\mathrm{E}$ & Correct \\
3327 & Intact & $\mathrm{C}$ & Correct \\
3819 & Absent/disrupted & $\mathrm{E}$ & Correct \\
3820 & Absent/disrupted & $\mathrm{C}$ & Incorrect \\
3821 & Absent/disrupted & $\mathrm{E}$ & Correct \\
3850 & Absent/disrupted & $\mathrm{E}$ & Correct \\
3851 & Absent/disrupted & $\mathrm{E}$ & Correct \\
3852 & Intact & $\mathrm{C}$ & Correct \\
3854 & Absent/disrupted & $\mathrm{E}$ & Correct \\
3855 & Absent/disrupted & $\mathrm{E}$ & Correct \\
3856 & Intact & $\mathrm{C}$ & Correct \\
4049 & Absent/disrupted & $\mathrm{E}$ & Correct \\
4050 & Intact/absent/disrupted & $\mathrm{C}$ & No prediction \\
& (mixed picture) & & made \\
4051 & Absent/disrupted & $\mathrm{E}$ & Correct \\
4100 & Absent/disrupted & $\mathrm{E}$ & Correct \\
4101 & Absent/disrupted & $\mathrm{E}$ & Correct \\
4102 & Absent/disrupted & $\mathrm{E}$ & Correct \\
\hline
\end{tabular}

KEY: $\mathrm{E}=$ experimental; $\mathrm{C}=$ control.

*Fifteen of 16 predictions were correct. The bladder mucin layer in all experimental animals was absent or significantly disrupted. The bladder mucin layer was fully intact in 3 of 5 control bladders and at least partially intact in 4 of 5 control bladders. The sole error in predictions was in Rabbit slide 3820 . Rabbit slide 4050 was the "mixed picture" on which no prediction was made.

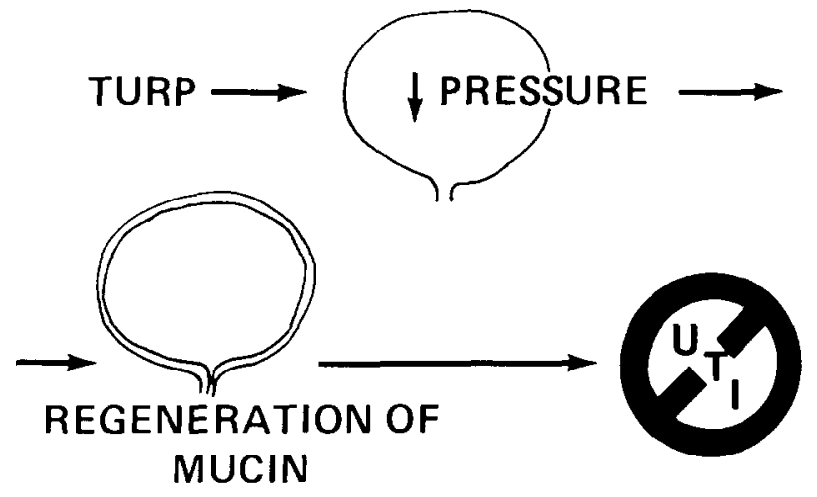

FIGURE 2. Transurethral prostatectomy may lower voiding pressure allowing mucin regeneration and resolution of previous urinary tract infection.

perhaps, infrequent voiding with destruction of this mucin layer. Previous studies have shown that destruction of this mucin layer causes increased bladder wall bacterial adherence. ${ }^{12,13}$ The implication that increased intravesical pressure, vesical overdistention, and infrequent voiding are related to urinary tract infections has been made before. ${ }^{8}$ These data depict a tenable pathophysiologic mechanism to support these implications.

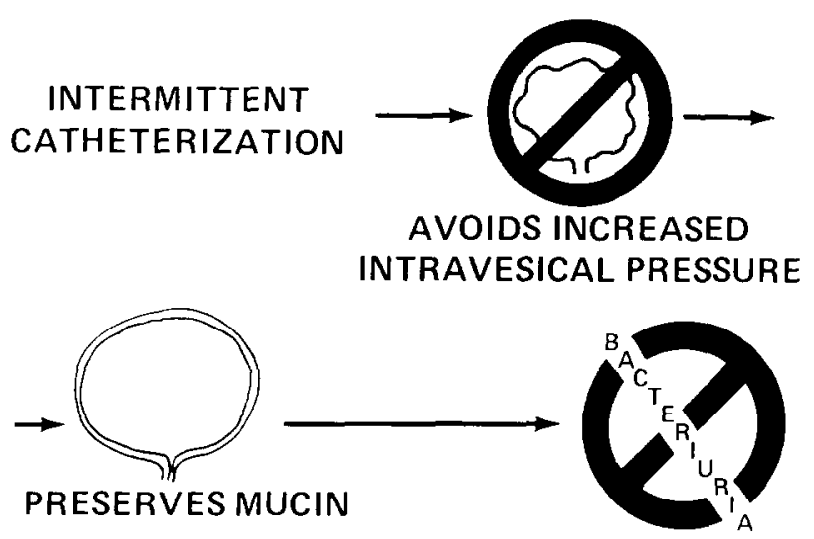

FIGURF 3. Intermittent catheterization may help avoid increased intravesical pressures, preserve mucin, and maintain uninfected urine.

Parsons and associates ${ }^{12}$ have shown the regeneration of the mucin layer to occur twentyfour hours after acid treatment. Perhaps a similar mucin regeneration occurs from the reduction of elevated voiding pressures after a transurethral prostatectomy, with eventual resolution of a previous urinary tract infection (Fig. 2). Finally, these data also would help to explain why many patients using intermittent catheterization maintain uninfected urine without the use of 
antibiotics, ${ }^{6}$ i.e., avoiding increased intravesical pressure and preserving the mucin (Fig. 3).

$4200 \mathrm{~W}$. Conejos Place Denver, Colorado 80204

(DR. PERLOW)

\section{References}

1. Corriere JW. MCClure JM III, and Lipshultz L: Contamination of bladder urine by urethral particles during voiding: urethrovesical reflux, J. Urol. 107: 339 (1972).

2. Stamey TA, Timothy M, Millar M, and Mihara G: Recurrent urinary infections in adult women: the role of introital enterobacteria, Calif. Med. 115: 1 (1971).

3. Cox $C F$ : The urethra and its relationship to urinary tract infection: the flom of the normal female urethra. South. Med. J. 59: $621(1966)$.

4. Cox CE. Lacy SS, and IIinman F Jr: The urethra and its relationship to urinary tract infection. II. The urethral flora of the female with recurrent urinary infection, J. Urol. 99: 632 (1968).

5. Cox CE, and Hinman $\mathbf{F}$ Jr: Experiments with induced bacteriuria, vesical emptying and bacterial growth on the mechanism of bladder defense to infection, ibid. 86: 739 (1961)

6. Lapides J. Diokno AC, Lowe BS, and Kalish MD: Follow-up on unsterile intermittent self-catheterization, ilid. 111: 184 (1974).

7. Mehrotra RML: An experimental study of the vesical circulation during distention and in cystitis, J. Pathol. Bacteriol. 66: 79(1953).

8. Lapides J: Mechanisms of urinary tract infection, Urology 14: $217(1979)$.

9. Hinman F Jr, and Cox CE: The voiding vesical defense mechanism; the mathematical effect of residual urine, voiding interval, and volume on bacteriuria. J. Urol. 96: 491 (1966).

10. Moore T, and Hira NR: The role of the female urethra in infection of the urinary tract, Br. J. Urol. 37: 25 (1965).

11. Boen JR, and Sylwester DL: The mathematical relationship among urinary frequency, residual urine, and bacterial growth in bladder infections, Invest. Urol. 2: 468 (1965).

12. Parsons CL, Greenspan C, Moore SW, and Mulholland SG: Role of surface mucin in primary antibacterial defense of bladder, Urology 9: 48 (1977).

13. Shrom SH, Parson CL, and Mulholland SG: Role of urothelial surface mucoprotein in intrinsic bladder defense. ibid 9: 526 (1977).

14. Parsons CL, Shrom SH, Hanno PM, and Mulholland SG: Bladder surface mucin, examination of possible mechanisms for its antibacterial effect, Invest. Urol. 16: 196 (1978).

15. Gillenwater JY, et al: Host antibacterial defenses of the lower urinary tract, in Greifer I(Ed): Bacteriuna and Urinary Tract Infections, Proceedings of the International Symposium of the National Kidney Foundation, National Kidney Foundation. New York, 1974. p. 125. 